\title{
LA DISCRIMINACIÓN MÚLTIPLE EN EL DERECHO AL ACCESO AL EMPLEO DE LA MUJER: UN ANÁLISIS DESDE EL ENFOQUE DE LA JUSTICIA RELACIONAL Y EL FEMINISMO
}

\author{
Multiple discrimination in women's right to access the labour market: an analysis from \\ relational justice approach and feminism
}

Recibido: 18 de junio de 2021

Aceptado: 21 de julio de 2021

Alejandra Ríos Pérez

Abogada

alejandrariospz@gmail.com

\section{RESUMEN}

Este trabajo combina el enfoque de la justicia relacional con el feminismo para evidenciar los vacíos de justicia que surgen en el acceso al empleo de la mujer y que impiden la consecución de la igualdad real. El principio de igualdad de trato tiene cierto arraigo en el ordenamiento jurídico español, aún así se siguen dando situaciones de discriminación por razón de género. Existen medidas y políticas encaminadas a combatir este tipo de discriminación, si bien no hay un sistema establecido para aquellos supuestos en los que varias circunstancias interaccionan y originan discriminación múltiple. Es necesario conocer estas situaciones y adoptar los mecanismos jurídicos para combatirlas y poder optar a la igualdad.

\section{PALABRAS CLAVE}

Justicia relacional, feminismo, discriminación múltiple, interseccionalidad, derecho al acceso al empleo.

\begin{abstract}
This paper combines the relational justice approach with feminism to highlight the justice gaps that arise in women's access to employment and that prevent the achievement of real equality. The principle of equal treatment has some roots in the Spanish legal system; even so, situations of gender-based discrimination continue to exist. There are measures and policies aimed at combating this type of discriminations, although there is not yet an established system for when various circumstances interact and give rise to multiple discriminations. It is necessary to be aware of these situations and to adopt mechanism to combat them in order to be able to opt for equality.
\end{abstract}

\section{KEYWORDS}

relational justice, feminism, multiple discrimination, intersectionality, right to access labour market. 
Sumario: 1. Introducción. 2. Combinación de enfoques: la justicia relacional y la teoría feminista. 2.1. La justicia relacional. 2.2. La teoría feminista. 2.3. Aporte entre enfoques. 3. Marco jurídico. 3.1. El marco internacional. 3.2. La regulación en la Unión Europea. 3.3. El ordenamiento jurídico español. 4. La discriminación de la mujer en el empleo. 4.1. El concepto de discriminación. 4.2. La situación de las mujeres en el acceso al empleo. 4.3. El tratamiento jurisprudencial de la discriminación múltiple. 5. Instrumentos de protección. 5.1. La actuación de la Inspección de Trabajo. 5.2. La vía judicial: el procedimiento de tutela de los derechos fundamentales. 6. Los vacíos de justicia. 7. Conclusiones.8. Bibliografía.

\section{Introducción.}

Aún persisten las diferencias por razón de sexo que originan la discriminación de la mujer. El bien jurídico a analizar es la igualdad de la mujer, en particular en el acceso al empleo. El mayor riesgo de exclusión social y de pobreza para esta con respecto al hombre es una de las evidencias de la desigualdad existente, para combatirla una de las principales vías que se presentan es el acceso a un empleo digno y de calidad, donde los datos manifiestan la existencia de una brecha de género. La mejora de la inserción de la mujer en el mercado de trabajo es un instrumento para conseguir unas condiciones materiales más prósperas y poder avanzar hacia la igualdad en esta dimensión. Esto permite un mayor empoderamiento y capacidad para decidir sobre todos los ámbitos de su existencia.

A la condición de mujer pueden sumarse diversas cualidades que dificultan más aún su integración en el mercado de trabajo, tales como la raza, la edad, la discapacidad, la clase social... Esta pluralidad de factores pueden articularse entre sí dando lugar a discriminaciones múltiples. La perspectiva de género ha ido ganando terreno y adquiriendo una posición transversal en el ordenamiento jurídico, al menos en el plano formal. Sin embargo, es necesario ahondar en aquellas otras condiciones que se alían con el género e incrementan la dificultad para acceder a un empleo digno.

El objetivo del presente artículo es desarrollar el concepto de la discriminación múltiple desde el enfoque de género, para poder observar los instrumentos existentes en el ordenamiento jurídico español para hacer frente a las situaciones de discriminación en el acceso al empleo y estudiar su cabida en los mecanismos de protección existentes. Subyace la idea de que la realización del principio de igualdad de la mujer en el acceso al empleo no puede alcanzarse si no se tiene en cuenta a todas las mujeres, con sus condiciones materiales y simbólicas particulares que pueden determinar una mayor dificultad para alcanzar un empleo digno.

Se parte de un enfoque de género que permite poner el énfasis en las desigualdades por razón de sexo, y se recurre a una concepción feminista de la justicia, con el objetivo de poner en valor los trabajos feminizados y señalar los riesgos de no tener en cuenta a los distintos grupos de mujeres, ya que esto puede ocasionar que en la búsqueda de la igualdad de la mujer acaben generándose dinámicas opresoras hacia las mujeres en situación de mayor vulnerabilidad. Esto se combina con la metodología propuesta por el enfoque de la justicia relacional que permite detectar los vacíos de justicia de la relación jurídica observando cómo es la interacción de las normas, cómo se articulan las relaciones sociales en base a estas y qué resultados arroja en términos de justicia.

El análisis de la legislación española sobre discriminación e igualdad de oportunidades, de la situación de la mujer, de la Jurisprudencia al respecto y de las posibles vías para reclamar ante una situación discriminatoria, permitirá observar la existencia de vacíos de 
justicia sobre los que profundizar para lograr la realización de la igualdad real, más allá de las condiciones particulares de cada persona.

\section{Combinación de enfoques: la justicia relacional y la teoría feminista}

El marco teórico para la realización del análisis planteado se base en la combinación del enfoque de la justicia relacional con la teoría feminista.

\subsection{La justicia relacional}

El punto de partida es el enfoque relacional de Pierpaolo Donati, quien se caracteriza por formar parte del "giro relacional" de la sociología. El pensar relacional se fundamenta en la importancia de la relación social en la producción del cambio social y como objeto autónomo de estudio; atribuyendo a la relación social las cualidades de referencia simbólica, vínculo estructural y su emergencia en la reciprocidad ${ }^{1}$. La aplicación de este enfoque a la justicia se basa en analizar la realización de la misma resaltando el comportamiento de los sujetos ${ }^{2}$.

La justicia relacional recoge la importancia de la relación social en cuanto motor del cambio social para aportar una nueva visión de la justicia que se caracteriza por ser multidimensional, buscar los vacíos de justicia a través de esa multidimensionalidad y ahondar en el estudio de la componente relacional -en la socialidad- de las relaciones jurídicas ${ }^{3}$.

La multidimensionalidad de este enfoque se concreta en tres dimensiones estrechamente relacionadas con los elementos de la relación social apuntados por Donati. Si para este la relación social se articula en base a tres semánticas ${ }^{4}$, en el enfoque de la justicia relacional, estas tres dimensiones, se articulan cono reciprocidad, institucionalidad y socialidad. La interacción de las mismas es la que da origen a la relación jurídica. Siendo importante el resaltar la necesidad de analizar de forma crítica las dimensiones y la interacción entre las mismas 5 .

La aplicación de este enfoque al Derecho del Trabajo conlleva la comprensión de la relación laboral como una relación social ${ }^{6}$, escapando de una concepción mercantilizada del trabajo por la cual la relación laboral es un intercambio más dentro del marco del mercado. En particular el enfoque de la justicia relacional aplicado al Derecho al Empleo, tal y como establece Salas Porras cuando aplica este enfoque a las políticas activas de empleo $^{7}$. En su trabajo, además relaciona las dimensiones de la relación jurídica con las

\footnotetext{
${ }^{1}$ Vid. DONATI, P. (2006), Repensar la sociedad: el enfoque relacional. Madrid: Ediciones Internacionales Universitarias, págs. 113-116. El estudio de la relación social debe hacer hincapié en la realidad de la relación, atribuyéndole estas tres cualidades.

${ }^{2}$ Vid. MÁRQUEZ PRIETO, A. (2017), "Justicia relacional: enfoque, línea y método”, en MÁRQUEZ PRIETO, A.: Justicia relacional y principio de fraternidad. Navarra: Aranzadi, pág. 160.

${ }^{3}$ Ibídem., pág. 185.

${ }^{4}$ Estas semánticas son la referencial, -entendida como significado e intenciones-, la estructural -basada en los vínculos y dependencias- y la generativa - el resultado de la relación-. Vid. DONATI, P. (2006), Repensar la sociedad: ... op. cit., págs. 115-116.

${ }^{5}$ Vid. MÁRQUEZ PRIETO, A. (2017), “Justicia relacional: enfoque, ... op. cit., pág. 185.

${ }^{6}$ Vid. SALAS PORRAS, M. (2017), "Replanteamiento jurídico de los fundamentos y finalidades de la política activa de empleo desde el enfoque de justicia relacional”, en MÁRQUEZ PRIETO, A.: Justicia relacional y principio de fraternidad. Navarra: Aranzadi, pág. 257.

${ }^{7}$ Sobre la aplicación del enfoque de la justicia relacional, esta académica establece que ello "conlleva identificar los elementos estructurales que corresponden a las tres dimensiones antes mencionadas, de forma que nos permita emitir un juicio sobre la adecuada adaptación entre sí de las dimensiones y sobre su
} 
áreas de las políticas activas de empleo, estableciendo así que la interacción entre actores se corresponde con la reciprocidad, la institucionalidad con las políticas públicas y las normas, y la socialidad con el mercado de trabajo ${ }^{8}$.

Tal y como propone Antonio Márquez, la justicia relacional se puede emplear como método para el análisis de las relaciones jurídicas ${ }^{9}$, haciendo hincapié en la distinción de las tres dimensiones jurídicas, al tiempo que no se pierda su visión de conjunto; en el análisis crítico de cada una de ellas para detectar los vacíos de justicia; y dirigiendo la argumentación en base a la dimensión de la institucionalidad. Tal metodología es la que se emplea, la profundización en las dimensiones de la relación jurídica laboral, en concreto, en el ámbito del acceso al empleo servirá para evidenciar los vacíos de justicia, es decir, aquellas situaciones de injusticia social, que pueden darse en cualquiera de las tres dimensiones de la relación ${ }^{10}$.

\subsection{La teoría feminista}

La existencia de desigualdades entre hombres y mujeres es un hecho constatable y fuertemente enraizado en diferentes sociedades, estas desigualdades son diversas manifestaciones de un mismo fenómeno, la subordinación de la mujer al hombre. La teoría crítica feminista parte de la existencia de una relación desigual en base al sexo-género cuya consecuencia es la opresión de la mujer. Desde este enfoque el objetivo es desvelar dichas relaciones de opresión para desmantelarlas.

Con respecto al papel del feminismo en relación con el campo del Derecho, establece Smart ${ }^{11}$ que no es necesario establecer una teoría feminista del Derecho, en tanto que la forma positivista del proceder en el Derecho encierra en cierta forma las cualidades que el sistema patriarcal atribuye a lo masculino, por lo que la búsqueda de una teoría feminista del Derecho supondría buscar la sustitución de una por otra, lo cual en sí se aleja del feminismo, que trata de abrir lo público a experiencias diversas ${ }^{12}$. Para esta autora el papel del feminismo en el ámbito del Derecho es diferente, necesita ser reconstruido y aplicar en este proceso el enfoque feminista, de modo que se evidencien los fundamentos patriarcales que han servido a su constitución ${ }^{13}$.

orientación a la justicia, [...] tomaremos como objeto de estudio un ámbito relacional más amplio que el de la relación interpersonal de trabajo." Ibídem, pág. 260.

8 "[L]a reciprocidad coincidiría con el grado de interacción entre actores sociales y económicos implicados en su configuración y materialización. En la dimensión de la relacionalidad se incluirían las propias políticas públicas y las normas que las ordenan. Por último, la dimensión de la socialidad contendría la red de relaciones creadas a partir de la interacción de las dos dimensiones anteriores, esto es, el mercado de trabajo y todas las relaciones sociales que lo crean y sostienen". Cuando esta autora se refiere a la dimensión de la relacionalidad está haciendo alusión a la antes llamada institucionalidad. Ibídem, pág. 260.

${ }^{9}$ Vid. MÁRQUEZ PRIETO, A. (2017), “Justicia relacional: enfoque, línea, método”... op. cit., pág. 198 y ss. La justicia relacional es al mismo tiempo enfoque, método y línea de investigación. En este análisis, si bien subyacen las otras dos naturalezas, tiene especial importancia la justicia relacional como método.

${ }^{10}$ Vid. RUIZ SANTAMARÍA, J. (2020), "El enfoque relacional como metodología de análisis en el Derecho del trabajo: el expediente de inclusión frente a la discriminación laboral” en Revista Jurídica de Investigación e Innovación Educativa (REJIE Nueva Época), núm. 21.

${ }^{11}$ Vid. SMART, C. (2017), "La búsqueda de una teoría feminista del derecho" en Delito y Sociedad, 1 (11/12), págs. 105-124.

12 Ibídem., pág. 108.

13 "El trabajo del feminismo es de-construir el discurso naturalísimo, negador del género del derecho, revelando constantemente el contexto en el cual ha sido constituido, y dibujando paralelos con otras áreas de la vida social. El derecho no es una entidad que flota libremente, está anclado en el patriarcado, así como en las divisiones de clase y las divisiones étnicas. No estoy segura de que debamos buscar una teoría feminista del derecho que debamos sustituir por esta totalidad”. Ibídem., pág. 122. 
El feminismo crítico se caracteriza por diferenciarse fuertemente del "feminismo liberal" en tanto que el objeto de este segundo es la consecución de la igualdad de mujeres y hombres en términos de mercado, lo cual solo supone un beneficio para aquellas mujeres que ya se encuentran posicionadas en un determinado nivel socioeconómico, sin tener en cuenta las condiciones materiales y sociales del resto de mujeres ${ }^{14}$. Este es el feminismo que se apoya en las cadenas de cuidados oprimiendo a otras mujeres para acceder al mundo de la producción en igualdad con los hombres, las tareas reproductivas se delegan en otras personas, fundamentalmente mujeres, en peor situación ${ }^{15}$.

Se trata de emplear el enfoque del feminismo que busca integrar los derechos de todo tipo de mujeres, indiferentemente de su clase social, género, raza, condición de migrante, orientación sexual, . ${ }^{16}$ La teoría feminista crítica ahonda en las desigualdades estructurales más allá del mercado, que además, suponen un condicionante de las desigualdades existentes en este.

Desde la perspectiva de las teorías de la justicia resulta enriquecedora la de Nancy Fraser, quien desde la teoría crítica y en sus análisis sobre la Justicia resalta la importancia de las injusticias derivadas del género. Fraser propone un interesante enfoque basado en tres dimensiones que puede ser de utilidad para articular el punto de partida del presente análisis. Establece la necesidad de entender el género desde una doble perspectiva, redistributiva y de reconocimiento ${ }^{17}$, con posterioridad añadirá una nueva dimensión a su enfoque de justicia, la representación ${ }^{18}$. La perspectiva redistributiva se fundamenta en la estructura económica de la sociedad, la del reconocimiento basa las diferencias de género en su interpretación cultural y de asignación de valores ${ }^{19}$ y la perspectiva de la representación es aquella referida a la participación en la esfera pública de las mujeres.

La propuesta de Fraser pasa por entender la justicia como una unión de estas dimensiones, y que esta puede alcanzarse a través del principio de paridad ${ }^{20}$. Esto implica la desaparición de las dependencias materiales -en relación con la dimensión redistributiva-; que los "patrones institucionalizados de valor que sistemáticamente

\footnotetext{
${ }^{14}$ Vid. ARRUZZA, C., BHATTACHARYA, T. y FRASER, N. (2019), Manifiesto de un feminismo para el 99\%. Herder Editorial, pág. 116.

15 Sobre las cadenas de cuidados se pronuncia Fraser estableciendo quienes desempeñan los trabajos de cuidados vacantes cuando una mujer se incorpora al mercado de trabajo, "[t]ípicamente son mujeres racializadas, a menudo de origen rural, de regiones pobres, las que asumen el trabajo reproductivo y de cuidados antes desempeñado por mujeres más privilegiadas. Pero para hacerlo, las migrantes deben transferir sus propias responsabilidades familiares y comunitarias a otras cuidadoras aún más pobres, que deben a su vez hacer lo mismo, y así sucesivamente, en <<cadenas de ciudades globales〉> cada vez más largas". Vid. FRASER, N. (2020), "Las contradicciones del capital y de los cuidados" en FRASER N. Los talleres ocultos del capital. Un mapa para la izquierda. Traficantes de Sueños, pág. 88.

${ }^{16}$ Vid. ARRUZZA, C., BHATTARCHARYA, T., y FRASER, N. ... op. cit., pág. 18.

${ }^{17}$ Vid. FRASER, N., (2012), "La política feminista en la era del reconocimiento: un enfoque bidimensional de la justicia de género" en Arenal. Revista de Historia de las Mujeres, núm. 19, vol. 2 julio-diciembre, pág. 272.

${ }^{18}$ Como recoge Clara Iglesias, esta autora en su obra ¿Redistribución o reconocimiento?, coescrita con Honnet, ya deja entrever su preocupación sobre la representación; posteriormente en Escalas de la Justicia, la representación cobra un importante papel como nueva dimensión de la justicia en el ámbito político. Vid. IGLESIAS, C., (2012), “Justicia como redistribución, reconocimiento y representación: las reconciliaciones de Nancy Fraser” en Investigaciones Feministas, vol. 3, pág. 256.

${ }^{19}$ Vid. FRASER, N. (2012), "La política feminista en la era del reconocimiento... op. cit., pág. 272.

${ }^{20}$ La paridad es aquí entendida no en términos cuantitativos, sino cualitativos, es decir, como la capacidad de actuar en "pie de igualdad" en todas las esferas de la vida. Vid. FRASER Vid. FRASER, N. (2012), "La política feminista en la era del reconocimiento... op. cit., pág. 276.
} 
desprecian ciertas categorías de personas y sus cualidades" ${ }^{21}$ también desaparezcan -esto se conecta con la dimensión del reconocimiento-; y todo ello teniendo en cuenta lo que posteriormente vendría a configurarse como la dimensión de la representación íntimamente relacionada con el principio de paridad-, orientada hacia la participación de todos los colectivos en la arena política, donde se decide sobre redistribución y reconocimiento.

\subsection{Aporte entre enfoques}

La combinación de la justicia relacional con la teoría crítica feminista puede resultar enriquecedora a la hora de profundizar en el estudio de los derechos de la mujer en el mercado de trabajo en todos sus ámbitos ${ }^{22}$. Partiendo de que el sistema de Derecho y el ámbito relacional laboral que se pretende estudiar se enmarca en un contexto patriarcal, tener presentes los principios de la teoría crítica feminista es sumamente interesante.

En primer lugar, esta unión sirve para justificar la importancia del análisis, basado en los déficits de justicia en el acceso de las mujeres al mercado de trabajo. Estos no se traducen exclusivamente en resultados materiales, sino que son expresión de unas relaciones desiguales y unos comportamientos que tienen un fuerte arraigo en nuestra sociedad, y por lo cual podemos calificarla de patriarcal. Por tanto, resultaría vacío analizar un problema como el que se plantea sin entrar a cuestionar las causas que lo originan, esto se solventa al introducir la teoría crítica feminista.

El empleo de esta perspectiva en el ámbito del Derecho contribuye a analizar aquellas formas de proceder patriarcales dentro del propio derecho, pero también más allá del mismo. Aplicar el método de la de-construcción a las relaciones jurídicas abarca las instituciones pero también las esferas de la socialidad en las que se enraízan las relaciones de opresión. La teoría feminista nos lleva a la aplicación de la perspectiva de género en el análisis, de modo que se centre el interés en la situación de la mujer en términos relativos con respecto a la del hombre. Esto permitirá localizar los sesgos que se encuentran en el ordenamiento jurídico y que originan los vacíos de justicia. ${ }^{23}$

Resultan aquí relevantes los conceptos de socialidad, planteado por el enfoque relacional, y de justicia de Nancy Fraser, expuesto anteriormente. La socialidad es importante en tanto marco estructural en el que se dan las relaciones jurídicas que pretendemos analizar - las de las mujeres en el ejercicio de su derecho al empleo-; y el concepto de justicia de Fraser porque propone un interesante análisis sobre cómo el género es origen de relaciones injustas en las distintas dimensiones de la justicia.

Esto enlaza con el segundo motivo por el cual esta combinación de enfoques resulta interesante, el aporte del feminismo pone el acento en la amplitud del sujeto cuyo acceso al empleo analizamos, de modo que a la hora de detectar los vacíos de justicia en el derecho

\footnotetext{
${ }^{21}$ Ibídem., pág. 275.

${ }^{22}$ Tal y como señalan Amorós y De Miguel la "teoría feminista no es un paradigma más al lado de otros, sino que se constituye en el Pepito Grillo de los demás paradigmas en cuanto sexistas o patriarcales". Vid. AMORÓS, C. y DE MIGUEL, A. (2014), Teoría feminista: de la ilustración al segundo sexo, vol. 1, pág. 18.

${ }^{23}$ Para una mayor profundización acerca de la perspectiva de género en el ámbito del Derecho del Trabajo, vid. RIVAS VALLEJO, P. (2020), "Perspectiva de género en el tratamiento de la discapacidad: incidencia laboral y de seguridad social" en La discapacidad en el marco de las relaciones laborales, octubrenoviembre. La profesora Rivas Vallejo pone como ejemplo de la importancia de introducir la perspectiva de género la aprobación de la Ley 27/2011, de 1 de agosto, sobre actualización, adecuación y modernización del sistema de Seguridad Social, señalando que al no tenerse en cuenta este enfoque se dificultó más aún el acceso de la mujer a las pensiones contributivas, incrementando con ello la brecha de género, pág. 11.
} 
de acceso de la mujer al empleo no basta con analizar el problema como una cuestión de realización de la igualdad de mujeres y hombres en su acceso al mercado de trabajo, sino que es necesario tener en cuenta otras identidades que pueden sumarse a la condición de mujer y que suponen un agravio comparativo a la hora de ejercer este derecho ${ }^{24}$.

Esto enlaza con la interseccionalidad de la discriminación propuesta por Kimberle Crenshaw en 1989, quien realiza una crítica al derecho antidiscriminatorio partiendo de la situación de las mujeres negras como sujeto de discriminación. Para este grupo de mujeres el marco unidimensional con el que se trabajaba en el derecho antidiscriminatorio resultaba insuficiente para analizar su realidad, ya que las situaciones de discriminación que podrían afectarles no siempre se referían exclusivamente a su condición de mujer o de persona racializada, sino que en ocasiones la intersección de ambas cualidades era la que las posicionaba en un lugar inferior con respecto al resto de la sociedad ${ }^{25}$. A la hora de abordar este estudio es necesario tener presente este planteamiento, para tener como meta el análisis de la igualdad en el acceso al empleo de todas las mujeres.

Los enfoques aquí planteados pueden maximizar su utilidad para abordar los problemas de justicia a los que se exponen determinados colectivos de mujeres en el acceso al mercado de trabajo.

\section{Marco jurídico}

La concepción de la protección de la mujer trabajadora ha evolucionado a lo largo de los años, al tiempo que lo ha ido haciendo el concepto de igualdad. Esta progresión se ha ido recogiendo en las normas internacionales y nacionales. A continuación se resaltan aquellas instituciones de los distintos órdenes jurídicos que afectan al Estado español ${ }^{26}$ y que se centran en la protección de la discriminación de la mujer en el trabajo.

\subsection{El marco internacional}

A nivel internacional, en particular en el marco de la OIT, se han adoptado distintos convenios para la protección de la mujer trabajadora ${ }^{27}$, si bien al hilo del presente artículo interesa especialmente el Convenio sobre la discriminación (empleo y ocupación) ${ }^{28}$, donde se obliga a promover la igualdad de oportunidades y de trato en materia de empleo y ocupación, eliminando las discriminaciones ${ }^{29}$, también se establecen como no discriminatorias aquellas medidas destinadas a satisfacer las necesidades particulares de

\footnotetext{
${ }^{24}$ En el momento de acceder al empleo la muere puede ser discriminada por su condición de mujer, pero también por otras cualidades, tales como la raza, el tener una discapacidad, la edad o la religión, entre otras. El hecho de no tener en cuenta cómo pueden interactuar estas características entre sí, puede originar nuevos vacíos de justicia en relación a determinados grupos de mujeres.

${ }^{25}$ Vid. CRENSHAW, K. (1989), "Demarginalizing the Intersection of Race and Sex: A Black Feminist Critique of Antidiscrimination Doctrine, Feminist Theory and Antiracist Politics" en University of Chicago Legal Forum, vol. 1989, art. 8, págs. 139-140.

${ }^{26}$ La protección de la mujer trabajadora se recoge en normativas a diversas escalas: la internacional, en concreto el marco de la OIT; a nivel europeo, a través de las normas e instituciones de la Unión Europea; y a nivel nacional.

27 Vid. C100-Convenio sobre igualdad de remuneración, 1951 (núm. 100) de la OIT o C103 sobre la protección de la maternidad (revisado, 1952 (núm. 103) de la OIT, ratificado por España en 1965, como ejemplos.

${ }^{28}$ Vid. C111-Convenio sobre la discriminación (empleo y ocupación), 1958 (núm. 111) de la OIT. Ratificado por España en 1967.

${ }^{29}$ Ibídem., art. 2.
} 
determinadas personas que por las mismas razones que puedan hallarse discriminadas se encuentran en necesidad de especial protección ${ }^{30}$.

El Convenio sobre política social ${ }^{31}$ marca como objetivo de la política social la supresión de la discriminación entre los trabajadores por motivos de raza, color, sexo, credo, asociación a una tribu o afiliación a un sindicato en los distintos ámbitos del trabajo, así como eliminar las diferencias salariales basadas en causas discriminatorias ${ }^{32}$.

Desde el marco de trabajo de la OIT cabe destacar además el Programa de Trabajo Decente. Se entiende trabajo decente como aquel centrado en cuatro pilares: creación de empleo, protección social, derechos en el trabajo y diálogo social ${ }^{33}$. Dentro de cada uno de estos objetivos existen diversas medidas que pueden implementarse para lograr la consecución de un trabajo digno. El trabajo decente se ha incluido como uno de los objetivos de las Naciones Unidas para la consecución del trabajo sostenible ${ }^{34}$, esto ha determinado que estados y organizaciones internacionales introduzcan este concepto en su discurso $^{35}$. Para la realización de este objetivo es imprescindible que el trabajo sea indisociable de determinados derechos, así como la eliminación de cualquier tipo de discriminación.

El trabajo decente como ODS incluye ya la perspectiva de género y ofrece datos sobre la participación de mujeres con respecto a la de los hombres en el mercado laboral ${ }^{36}$. Dentro de las metas específicas de este Objetivo se insertan el principio de igual remuneración por trabajo de igual valor, también se pone el enfoque en la doble discriminación de las mujeres migrantes al tratar sobre la protección de los derechos laborales y la promoción de un entorno de trabajo seguro y sin riesgos para todos los trabajadores, haciendo hincapié en "los trabajadores migrantes, en particular las mujeres migrantes y las personas con empleos precarios" 37 .

\subsection{La regulación en la Unión Europea}

El ordenamiento de la UE contiene de forma dispersa distintas disposiciones en materia de igualdad de trato y derecho antidiscriminatorio, tanto en el derecho originario ${ }^{38}$ como en el derivado y en la Carta de los Derechos Fundamentales de la Unión Europea ${ }^{39}$.

De ahí se deriva la consagración del principio de igualdad entre hombres y mujeres, incluyendo el ámbito del acceso al empleo ${ }^{40}$. El derecho antidiscriminatorio de la Unión

\footnotetext{
${ }^{30}$ Ibídem., art. 5.

31 Vid., C117-Convenio sobre política social (normas y objetivos básicos), 1962 (núm. 177) de la OIT. Ratificado por España en 1973.

${ }^{32}$ Ibídem., art. 14.

${ }^{33}$ El concepto de "trabajo decente" fue introducido por el director general de la OIT Juan Somaravia en 1999 y hace referencia al empleo digno.

${ }^{34}$ En los Objetivos de Desarrollo Sostenible adoptados en 2015, el número 8 es el trabajo decente y crecimiento económico.

35 Vid. MORÁN BLANCO, S. (2018), "El <<trabajo decente〉> en la UE: políticas y normas" en Revista Española de Derecho del Trabajo, núm. 206/2018 parte Estudios.

${ }^{36}$ Según un informe del Programa de Naciones Unidas para el Desarrollo "La participación de las mujeres en la fuerza laboral fue del $48 \%$ en 2018 , en comparación con el $75 \%$ de los hombres" [en línea] https: //www.undp.org.content/undp/es/home/sustainable-development-goals.html.

${ }^{37}$ Ibídem.

${ }^{38}$ Vid., Tratado de Funcionamiento de la Unión Europea (arts. 8, 151 y siguientes) y Tratado de la Unión Europea (arts. 2 y 3 ).

${ }^{39}$ Vid., capítulo III.

40 Vid., Directiva 75/177/CEE del Consejo de 10 de febrero de 1975 relativa a la aproximación de las legislaciones de los Estados miembros que se refieren a la aplicación del principio de igualdad de retribución
} 
recoge también las definiciones de discriminación directa e indirecta y discriminación múltiple ${ }^{41}$ y la inversión de la carga de la prueba en los supuestos de discriminación por razón de $\operatorname{sexo}^{42}$.

El último instrumento jurídico relevante en lo relativo a la discriminación es la propuesta de Directiva del Consejo por la que se aplica el principio de igualdad de trato entre las personas independientemente de su religión o convicciones, discapacidad, edad u orientación sexual. Si bien esta propuesta excluye de su ámbito de aplicación el empleo y la ocupación por entender que estos ya están protegidos en otras disposiciones ${ }^{43}$, la importancia de esta propuesta reside en la definición de distintos tipos de discriminación y su incidencia en la discriminación múltiple. Esta Directiva marca de forma determinante la dirección de la Unión en los próximos años en relación con el derecho a la igualdad de trato y la eliminación de toda forma de discriminación.

Tal y como señala Sandra Fredman ${ }^{44}$ existen obstáculos a la aplicación de la discriminación múltiple en el ordenamiento europeo. Los principales inconvenientes son la dispersión de las normas, pues como se ha expuesto existe una gran variedad de Directivas que tratan la materia; cada disposición persigue un objetivo, lo cual atiende a su distinto momento de adopción y motivaciones de fondo; se da un tratamiento diferente a cada causa de discriminación; los motivos de discriminación están tasados; y la dificultad de establecer en relación a quién se realiza la comparación para determinar si existe o no una diferencia de trato.

\subsection{El ordenamiento jurídico español}

La Constitución española establece el principio de no discriminación por razón de sexo en su artículo 14 y en el artículo 35 prohíbe la discriminación por este motivo en el trabajo. A su vez, son varias las normas que contienen disposiciones en relación a la mejora de las condición de la mujer en el mundo del trabajo ${ }^{45}$. Además, la Ley Orgánica para la igualdad

entre los trabajadores masculinos y femeninos; Directiva 76/207/CEE del Consejo de 9 de febrero de 1976 relativa a la aplicación del principio de igualdad de trato entre hombres y mujeres en lo que se refiere al acceso al empleo, a la formación y a la promoción profesionales, y a las condiciones de trabajo; Directiva 2002/73/CE del Parlamento Europeo y del Consejo de 23 de septiembre de 2002 que modifica la Directiva 76/207/CEE del Consejo relativa a la aplicación del principio de igualdad de trato entre hombres y mujeres en lo que se refiere al acceso al empleo, a la formación y a la promoción profesionales, y a las condiciones de trabajo.

${ }^{41}$ Vid., Directiva 2000/43/CE del Consejo de 29 de junio de 2000 relativa a la aplicación del principio de igualdad de trato de las personas independientemente de su origen racial o étnico y Directiva 2000/78/CE del Consejo de 27 de noviembre de 2000 relativa al establecimiento de un marco general para la igualdad de trato en el empleo y la ocupación.

${ }^{42}$ Vid., Directiva 97/80/CE del Consejo de 15 de diciembre de 1997 relativa a la carga de la prueba en los casos de discriminación por razón de sexo.

${ }^{43}$ En el marco de las negociaciones, el Consejo acuerda que lo adoptado por esta Directiva pueda contribuir a la promoción del principio de igualdad de trato en el ámbito del empleo y la ocupación. Vid. HERBOSA MARTÍNEZ, I., (2020), "Una primera aproximación a la propuesta de Directiva del Consejo por la que se aplica el principio de igualdad de trato entre las personas independientemente de su religión o convicciones, discapacidad, edad u orientación sexual”, en Revista Aranzadi Unión Europea, núm, 5/2020 parte Doctrina, pág. 2.

${ }^{44}$ Vid. FREDMAN, S. (2016), "Intersectional discrimination in EU gender equality and non-discrimination law”, en Directorate-General for Justice and Consumers, págs. 62-65.

45 Vid., Ley 31/1995, de 8 de noviembre, de prevención de Riesgos Laborales; Ley 39/1999, de 5 de noviembre, para promover la conciliación de la vida familiar y laboral de las personas trabajadoras; Real Decreto-ley 6/2019, de 1 de marzo, de medidas urgentes para garantía de la igualdad de trato y oportunidades entre mujeres y hombres en el empleo y la ocupación; Real Decreto Legislativo 3/2015, de 23 de octubre, por el que se aprueba el texto refundido de la Ley de Empleo; Real Decreto 902/2020, de 13 de octubre, de igualdad retributiva... 
efectiva de mujeres y hombres ${ }^{46}$, cuyo eje básico es el principio de igualdad de $\operatorname{trato}^{47} \mathrm{y}$ que tiene vocación de transversalidad ${ }^{48}$, hace referencia a la discriminación múltiple ${ }^{49} \mathrm{y}$ dedica su Título IV a "El derecho al trabajo en igualdad de oportunidades" y el Título V a "El principio de igualdad en el empleo público".

Al tratar sobre igualdad en el empleo resulta imperativo detenerse en el Estatuto de los Trabajadores ${ }^{50}$. En su artículo 4, sobre derechos laborales, dispone en su apartado 2.c) el derecho a la no discriminación que ostentan todas las personas trabajadoras; y en el 17 se recoge la prohibición de la discriminación en las relaciones laborales y sus consecuencias. A lo largo de todo su articulado se recogen distintas medidas para la realización del principio de igualdad de trato entre hombres y mujeres ${ }^{51}$.

Cabe hacer mención a la Ley sobre Infracciones y Sanciones en el Orden Social ${ }^{52}$, donde se tipifican como sanciones muy graves aquellas conductas discriminatorias, directas e indirectas, y las decisiones que supongan un trato desfavorable de los trabajadores por reclamar el cumplimiento de los principios de igualdad de trato y no discriminación ${ }^{53}$; estableciendo además este tipo de sanción para otras conductas cuyo origen se encuentra en la desigualdad por razón de sexo. En relación al acceso al empleo, la sanción se centra en la petición de datos de carácter personal o el establecimiento de condiciones en los procesos selectivos que impliquen discriminación ${ }^{54}$.

A pesar de que en el ordenamiento jurídico español existan múltiples medidas para tratar de paliar las desigualdades y discriminaciones existentes por razón de sexo, a la hora de atender a la combinación de distintas causas que puedan incrementar lo injusto de una conducta discriminatoria, no hay instrumentos en la legislación. En la actualidad, en la LOI en la Exposición de Motivos II recoge el concepto de discriminación múltiple, lo cual puede constituir un punto de partida.

\section{La discriminación de la mujer en el empleo}

La protección de la mujer en el Trabajo ha evolucionado desde la percepción de la mujer como un ser subordinado al hombre y necesitada de protección basado en el constructor de la fragilidad de la mujer y su condición de madre ${ }^{55}$.

\footnotetext{
${ }^{46}$ Ley Orgánica 3/2007, de 22 de marzo, para la igualdad efectiva de mujeres y hombres, en adelante LOI.

${ }^{47}$ Ibídem., art. 3.

${ }^{48}$ Ibídem., art. Exposición de Motivos III.

${ }^{49}$ Ibídem., Preámbulo y art. 14.6.

${ }^{50} \mathrm{Vid}$. Real Decreto Legislativo 2/2015, de 23 de octubre, por el que se aprueba el texto refundido de la Ley del Estatuto de los Trabajadores.

${ }^{51}$ Como por ejemplo el mecanismo corrector de los sistemas de calificación profesional (art. 22), la ausencia de discriminación en ascensos y promociones (art. 24), principio de igual de retribución por igual trabajo (art. 28), derecho a la conciliación de la vida familiar y laboral (art. 34), información sobre el derecho a la igualdad de trato (art. 64.3).

${ }^{52}$ Vid. Real Decreto Legislativo 5/2000, de 4 de agosto, por el que se aprueba el texto refundido de la Ley sobre Infracciones y Sanciones en el Orden Social.

53 Ibídem., art. 8.12.

${ }^{54}$ Ibídem., art. 16.1.c).

${ }^{55}$ Vid. ALEMANY ZARAGOZA, E. (2005) "Evolución histórica del trabajo de la mujer hasta nuestros días", en Revista Doctrinal Aranzadi Social, núm. 22/2004 parte Estudio, p.13. En relación con esta concepción de la mujer, es interesante resaltar como FRASER Nancy. "Las contradicciones del capital...op. cit., pág. 79 atribuye en parte esta protección de la mujer en el trabajo como consecuencia de la crisis reproductiva que acarreaban las nefastas condiciones de trabajo de mujeres y niños en las fábricas, que amenazaba la institución familiar burguesa.
} 
La integración de la mujer al trabajo productivo ${ }^{56}$ durante las revoluciones industriales supuso la consagración de la doble jornada de la mujer en dos esferas, en la del trabajo productivo y el reproductivo ${ }^{57}$. La situación ha sido fluctuante desde entonces, con mayor promoción del trabajo femenino en aquellos períodos donde fue más necesaria la mano de obra -tales como períodos de conflictos bélicos o de gran crecimiento económico ${ }^{58}$-. Este desarrollo de la situación económica y los movimientos sociales han llevado a que en los últimos años se hayan incluido medidas de promoción de la igualdad, políticas activas, las medidas de conciliación familiar persiguen un reparto de tareas equitativo, etc., lo cual evidencia un cambio de paradigma con respecto a las primeras medidas protectoras de la mujer en el empleo.

\subsection{El concepto de discriminación}

La desigualdad que hoy día se sigue manifestando entre mujeres y hombres se materializa en discriminación por razón de sexo, la cual se encuentra en todas las esferas de la vida, y también en el acceso al empleo y en la calidad del mismo.

La discriminación se da de distintas formas, por un lado están las ya conocidas variantes de discriminación directa e indirecta ${ }^{59}$. El elemento determinante en la discriminación directa es el "trato menos favorable", este concepto se entiende en términos relativos y precisa de comparación con otras personas en la misma situación pero cuyo trato difiera ${ }^{60}$. La discriminación indirecta es el efecto de un trato igual, es decir, aquellas ocasiones en las que no tener en cuenta las condiciones de partida de un determinado grupo hace que las medidas genéricas le creen una situación desfavorable o dificulten el acceso a algún servicio $^{61}$. Por otro lado se encuentran aquellas situaciones discriminatorias en las que influyen más de una causa de discriminación. Sandra Fredman señala tres: la discriminación secuencial múltiple, en la que una persona sufre discriminación por diferentes motivos en momentos separados; la discriminación múltiple aditiva, cuando una persona en una misma situación es discriminada por dos o más razones diferentes; y la discriminación interseccional ${ }^{62}$, que es aquella que se da cuando la interacción de dos o

\footnotetext{
56 La expresión "trabajo productivo" se usa en contraposición con "trabajo reproductivo", conceptos empleados por FRASER, Nancy. "Las contradicciones del...op. cit., pág.76, para diferenciar el trabajo de reproducción económica, el remunerado, del trabajo de reproducción social, remunerado con la moneda del $\langle\langle$ amor $\rangle>$ y la $\langle\langle$ virtud $\rangle$ >. El trabajo reproductivo es aquel asociado a todas las funciones necesarias para el cuidado de la vida, tradicionalmente asociado a la mujer.

${ }^{57}$ Vid. ALEMANY ZARAGOZA, E. (2005) "Evolución histórica del trabajo de...op. cit. pág.4.

58 Como ejemplo, la expansión económicas de los años sesenta en España requirió de una mayor incorporación de la mujer al mercado laboral y esto trajo consigo medidas como la revocación de la excedencia forzosa por matrimonio. Ibídem., pág. 6.

${ }^{59}$ Vid. Artículo 2 de la Directiva 2000/78/CE del Consejo de 27 de noviembre de 2000, para la igualdad de trato en el empleo y la ocupación se definen ambos tipos, siendo la discriminación directa aquella que se da "cuando una persona sea, haya sido o pudiera ser tratada de manera menos favorable que otra en situación análoga por alguno de los motivos mencionados en el artículo 1"; y la indirecta "cuando una disposición, criterio o práctica aparentemente neutros pueda ocasionar una desventaja particular a personas con una religión o convicción, con una discapacidad, de una edad, o con una orientación sexual determinadas, respecto de otras personas (...)”.

${ }^{60} \mathrm{Vid}$. AGENCIA DE LOS DERECHOS FUNDAMENTALES DE LA UNIÓN EUROPEA (2011), "Manual de legislación europea contra la discriminación”, Luxemburgo, pág. 23.

${ }^{61}$ Ibídem., pág. 29.

${ }^{62}$ Este tipo de discriminación parte de la insuficiencia del enfoque unicausal del derecho antidiscriminatorio, Crenshaw parte de la realidad de las mujeres negras como grupo en el que concurren dos causas discriminatorias de forma interseccional y resalta cómo el no tener en cuenta la interseccionalidad impide una correcta apreciación de ciertos supuestos discriminatorios. Esto se produce porque para apreciar una situación de discriminación se realiza una comparación con el grupo privilegiado; para el caso de las mujeres negras, hay momentos en los que la discriminación que estas sufren no se hace patente al compararla con la
} 
más causas discriminatorias originan un tipo particular de discriminación diferentes de las causas originarias iniciales, siendo la combinación de ambas en una misma persona lo que origina el trato diferenciado ${ }^{63}$. Esta última es la que presenta mayores problemas para encajar en los ordenamientos jurídicos existentes, con el riesgo de que se invisibilicen este tipo de situaciones ${ }^{64}$.

Jiménez Rodrigo ha tratado el tema de la discriminación múltiple en el empleo y señala la necesidad de ampliar la definición operativa de trabajo, para poder incluir así aquellos trabajo no regularizados ${ }^{65}$. Además, establece tres momentos de la relación laboral en los que puede darse la situación de discriminación: en el acceso al empleo y la segmentación del mercado de trabajo, condiciones de empleo y a la hora de dar respuesta a la discriminación ${ }^{66}$. En el presente estudio se presta mayor atención al acceso al empleo, sin embargo, para que la inserción al mercado se produzca en condiciones de igualdad es necesario no perder una visión holística de las tres áreas.

\subsection{La situación de las mujeres en el acceso al empleo}

La brecha de género ocasiona un mayor riesgo de exclusión social y pobreza, esta brecha es de $11 \%$ en relación a la tasa de empleo ${ }^{67}$. Existe además, una menor participación de la mujer en el mercado de $\operatorname{trabajo}^{68}$ y determinados sectores están altamente feminizados.

Esto esboza una situación de la mujer en el mercado de trabajo en la que se aprecia una menor inserción que el hombre, con una participación y ausencia en sectores muy determinados, lo que se corresponde con los valores culturales acerca de los trabajos que tradicionalmente han desempeñado - o no han podido desempeñar- las mujeres. A la menor inserción laboral cabe añadir la brecha salarial y el mayor porcentaje de temporalidad de los contratos.

Si además se aprecian otras circunstancias concurrentes en las mujeres la inserción en el mercado de trabajo empeora. Así, la tasa de empleo disminuye con la edad y la brecha de género se acentúa ${ }^{69}$. Las mujeres migrantes tienen una tasa de ocupación que se caracteriza por su irregularidad ${ }^{70}$; un alto porcentaje de este grupo de mujeres se concentra

de las mujeres blancas, por tanto se descarta la discriminación por razón de sexo; ni tampoco al compararla con la del hombre negro, esto lleva a que la situación de vulnerabilidad quede invisibilizada al no encajar en ninguna de las categorías. Vid. Vid. CRENSHAW, K., (1989), "Demarginalizing the Intersection ... op. cit.

${ }^{63} \mathrm{Vid}$. FREDMAN, S. (2016), "Intersectional discrimination in EU gender equality and non-discrimination law”, Directorate-General for Justice and Consumers, págs. 27-28.

${ }^{64}$ Ibídem., pág. 28.

${ }^{65}$ Vid. JIMÉNEZ RODRIGO, M. (2018) "El abordaje de la discriminación múltiple en el empleo: Revisión de políticas y buenas prácticas en la Unión Europea” en Revista Internacional y Comparada de Relaciones Laborales y Derecho del Empleo, vol. 6, núm. 3, julio-septiembre, pág. 205. "Esta mirada [hacia las intersecciones entre distintas causas de discriminación] obliga a cuestionar las definiciones convencionales de trabajo ligadas a la "norma social" del empleo para incluir otros "trabajos" ubicados en mercados laborales informales, marginales e ilegales, como por ejemplo, la prostitución o las situaciones de trata y explotación con fines laborales o sexuales".

${ }^{66}$ Ibídem., pág. 206.

${ }^{67}$ Datos del INE a 2019.

${ }^{68}$ La tasa de actividad de las mujeres en España en el 2019 era de 53\% mientras que la de los hombres era del 64\%, según los datos del INE.

${ }^{69}$ La brecha de género es de $11,6 \%$ para el intervalo de edad entre 25 y 54 años y de $14,2 \%$ para el intervalo de 55 a 64 años, según los datos del INE de 2019.

${ }^{70}$ La tasa de ocupación es del 48\%, un $14 \%$ están empleadas de forma informal y un 38\% en situación de desempleo. Vid. ORGANIZACIÓN INTERNACIONAL PARA LAS MIGRACIONES (2016), Estudio sobre la situación laboral de la mujer en España, Ministerio de Empleo y Seguridad Social, pág. 23. 
en el sector del empleo doméstico ${ }^{71}$, notable por su precariedad y que en ocasiones lleva a las trabajadoras a situaciones de abuso y maltrato ${ }^{72}$. La orientación sexual también puede ser un condicionante para el aumento de la discriminación laboral -incluyendo el acceso al empleo-, agravándose en el caso de la mujeres ${ }^{73}$.

Sin necesidad de hacer enumeraciones exhaustivas estos ejemplos dejan patente la existencia de situaciones en las que se da una conducta más injusta por originarse en más de una causa de discriminación.

\subsection{El tratamiento jurisprudencial de la discriminación múltiple}

Dado el escaso alcance de la discriminación múltiple en el plano normativo, es necesario acudir a la Jurisprudencia para observar su desarrollo en estos términos.

En el plano internacional destaca la sentencia de la sección tercera del Tribunal Europeo de Derechos Humanos del caso B.S. contra España ${ }^{74}$, en la que la demandante, una mujer de origen nigeriano que se dedicaba a la prostitución, alega haber sufrido discriminación por la triple condición de sexo, raza y ocupación. Los terceros participantes instaron al Tribunal a considerar la discriminación múltiple, pues tomados de forma individual los elementos discriminatorios podrían no arrojar luz sobre la discriminación acontecida ${ }^{75}$.

En el contexto español, el Tribunal Constitucional reconoce la existencia de discriminación múltiple en su Sentencia 3/2018, de 22 de enero ${ }^{76}$, en la que se pronuncia sobre un caso donde concurren discapacidad y edad como causas discriminatorias, y se resalta la necesidad de no descartar la variedad de combinaciones que pueden darse entre las causas discriminatorias.

La Jurisprudencia menor también recoge este concepto. La Sentencia del Tribunal Superior de Justicia de las Islas Canarias, de 4 de junio de $2018^{77}$ recoge un voto particular, de la magistrada Gloria Poyatos Matas, en el que se pronuncia acerca de la discriminación múltiple indirecta que sufrió una trabajadora, camarera de hotel, al ser sancionada por baja productividad. Las dos condiciones que reunía la trabajadora eran ser mujer y tener 61 años, reflejando la magistrada que el no tener "en cuenta las condiciones personales de las trabajadoras afectadas, tales como la edad, [genera] un subgrupo de mujeres doblemente discriminadas" $" 78$.

La Sentencia del Tribunal Superior de Justicia de Cataluña, de 2 de mayo de $2017^{79}$ sobre un caso de despido nulo por vulneración del derecho fundamental a la libertad sindical la tutela judicial efectiva y a no sufrir discriminación por razón de sexo se pronuncia sobre la discriminación múltiple. En primer lugar se reconoce que los efectos de

\footnotetext{
${ }^{71}$ Ibídem., pág. 26.

${ }^{72}$ Vid. NOGUEIRA DOMÍNGUEZ, J. y ZALAKAIN HERNÁNDEZ, J. (2015) “La discriminación múltiple de las mujeres extranjeras que trabajan en servicios domésticos y de cuidados a dependientes en Euskadi" en Zerbitzuan: Gizarte zerbitzuetarako aldizkaria, núm. 60, pág. 160.

73 Vid. UGT, Área Confederal LGTBI. Disponible en: https://www.ugt.es/sites/default/files/resumen_ejecutivo1.pdf.

${ }^{74}$ Vid. Sentencia de la sección tercera del TEDH Asunto Beauty Salomon contra España, nº 47159/08, 24 de julio de 2012.

${ }^{75}$ Ibídem., parrs. 65 y 66.

${ }^{76}$ Publicada en el BOE núm. 46, de 21 de febrero de 2018.

${ }^{77}$ Vid. Sentencia del Tribunal Superior de Justicia de las Islas Canarias, de 4 de junio de 2018. № de Recurso: $1739 / 2017$.

${ }^{78}$ Ibídem., pág. 12.

79 Vid. Sentencia del Tribunal Superior de Justicia de Cataluña, de 2 de mayo de 2017N ${ }^{\circ}$ de Recurso: $818 / 2017$.
} 
la discriminación unidimensional no son los mismos que los de la múltiple ${ }^{80}$, y posteriormente, en el Fundamento de Derecho $5^{\circ}$ se hace referencia a la existencia de discriminación múltiple cumulativa y a su escasa mención en la normativa, que aún así permite la apreciación de la misma.

\section{Instrumentos de protección}

Las Directivas europeas de derecho antidiscriminatorio establecen la obligación de los Estados miembro de fijar medidas para garantizar que se cumple el principio de igualdad de trato y no discriminación. En el ordenamiento jurídico español estos mecanismos, en el ámbito del acceso al empleo, se encuentran en las sanciones previstas en la LISOS; además, para la tutela por la vía judicial existen diversos procedimientos, si bien aquí se pone el énfasis en el procedimiento de tutela de los derechos fundamentales.

\subsection{La actuación de la Inspección de Trabajo}

La Inspección de Trabajo y Seguridad Social ${ }^{81}$ es encargada de velar por la realización del principio de igualdad de trato dentro del marco del empleo. La actuación de la IT en esta materia viene marcada por la Instrucción 3/2011, sobre actuaciones de la Inspección de Trabajo y Seguridad Social para la vigilancia en las empresas de la igualdad efectiva entre mujeres y hombres aprobada por la Dirección General de Inspección de Trabajo, así como el resto de disposiciones que regulen este ámbito.

Esta Instrucción establece la actuación de la IT en los diversos ámbitos del empleo, en relación al acceso al empleo la IT debe velar por que no haya ofertas de empleo discriminatorias ${ }^{82}$. Cuando la IT detecta situaciones de discriminación en el acceso al empleo realiza un acta de inspección y antes de que exista una resolución administrativa firme, da cuenta al Juzgado de lo Social de ello, comunicando las razones en las que se debería basar la posible indemnización. Será el Juzgado el encargado de determinar la indemnización correspondiente, no siendo objeto del proceso la determinación de la existencia de una conducta sancionable o no. Esta sentencia será de carácter declarativo y no condenatoria y se le comunicará a la Autoridad Laboral correspondiente para que prosiga con el procedimiento sancionador ${ }^{83}$.

\subsection{La vía judicial: el procedimiento de tutela de los derechos fundamentales}

La tutela judicial de la igualdad de trato y oportunidades en los Tribunales es una cuestión compleja e imperfecta. En la jurisdicción social son varios los procedimientos los que se puede recurrir para reclamar la vulneración por discriminación, este estudio se centra en la tutela de los derechos fundamentales y las libertades públicas, regulado en los artículos 177 al 183 de la Ley 36/2011, de 10 de octubre, reguladora de la jurisdicción social.

Este proceso es garantista y está dotado de elementos que velan por la realización de la protección debida, tales como la inversión de la carga de la prueba, recogida en la

\footnotetext{
${ }^{80}$ Ibídem., pág.11.

${ }^{81}$ En adelante IT.

${ }^{82}$ Vid. art. 16.1.c) de la LISOS.

${ }^{83}$ Vid. APECECHEA CELAYA, C. (2016), "Actuaciones de la Inspección de trabajo y Seguridad Social para la vigilancia en las empresas de la igualdad entre mujeres y hombres" en Estudios sobre los diversos aspectos jurídicos del trabajo de la mujer, Aranzadi, Enero, pág. 19.
} 
normativa nacional y comunitaria ${ }^{84}$; la legitimación activa es amplia y permite que la acción se interponga por diversos actores, desde la persona individual afectada, hasta las asociaciones por la defensa de igualdad de trato, pasando por los sujetos colectivos ${ }^{85}$.

La particularidad del ámbito del acceso al empleo es compleja, en tanto que es una situación donde pueden llegar a difuminarse la discriminación y la libertad de contratación de la empresa, si bien, el principio de igualdad de trato se extiende a toda la relación laboral, incluido el acceso al empleo ${ }^{86}$. En este sentido, la jurisprudencia constitucional recoge que el respeto a los derechos fundamentales, y el derecho a la igualdad, constituyen un límite a la libertad de contratación del empresario ${ }^{87}$. No existiendo así tal colisión de derechos, sino una conducta injusta, por basarse en un elemento diferenciador como puede ser la raza o el sexo, lo cual no puede disfrazarse de preferencia para el desempeño de un empleo en determinadas ocasiones.

El recurrir al procedimiento de tutela de derechos fundamentales, supone que la protección debe venir por la triple vía del artículo 182 de la Ley reguladora de la jurisdicción social, consistente en: la nulidad de la acción que ocasiona la vulneración, la restitución de la situación al momento en que se produjo dicha vulneración y el resarcimiento de los daños y perjuicios causados ${ }^{88}$. No siempre podrán darse todas.

Por su vinculación con el objeto de estudio, la discriminación múltiple, interesa especialmente el cómo se establece el resarcimiento, para poder valorar si la acumulación de causas discriminatorias puede permitir un incremento de las cantidades en concepto de daños y perjuicios. La indemnización en la jurisdicción laboral se rige actualmente por el principio de la restitutio in integrum ${ }^{89}$, para este proceso recogido en el artículo 183 de la Ley reguladora de la jurisdicción social. En este artículo se recoge que es deber del juez establecer la cuantía indemnizatoria cuando haya habido vulneración, esta indemnización incluye el daño moral, así como los daños y perjuicios adicionales derivados -daño emergente y lucro cesante-. El objetivo es el resarcimiento a la víctima, y siempre que sea posible la restitución a la situación anterior. La tercera dimensión de la indemnización sería su carácter disuasorio, requerido por las normas comunitarias.

Existe un deber legar de establecer medidas restitutorias y disuasorias ${ }^{90}$, el establecer la obligación de contratar como medida restitutoria puede resultar problemático. En aquellos casos en los que la obligación pueda afectar a terceros, no cabría plantear esta medida; sin embargo, cuando aún fuera posible instar la contratación, serían diversos los elementos a ponderar, tales como las oportunidades de trabajo ${ }^{91}$.

A la hora de fijar la cuantía indemnizatoria, dado el escaso desarrollo normativo, es necesario recurrir a la jurisprudencia. La Sentencia de la Sala de lo Social del Tribunal

\footnotetext{
${ }^{84}$ A nivel comunitario, en un primer momento, se fijó en la Directiva 97/80/CE, posteriormente, la inversión de la carga de la prueba en los casos de discriminación pasó a regularse en la Directiva 2006/54/CE. En la legislación española esto se refuerza con el art. 13 de la LOI.

${ }^{85}$ Vid. ARANZADI. "La tutela judicial laboral antidiscriminación en el acceso a un puesto de trabajo a través del proceso de tutela de derechos fundamentales y libertados públicas". En Cuadernos de Aranzadi Social. Estadios previos al contrato de trabajo y discriminación, enero de 2013, págs. 7-10.

${ }^{86}$ Vid. RODRÍGUEZ CRESPO, M. "Límites a la libertad contractual: igualdad y no discriminación en materia de intermediación, selección y contratación" en Revista Doctrinal Aranzadi Social núm. 2/2013 Informes, 2013, pág. 2.

${ }^{87}$ Ibídem., pág. 4.

${ }^{88} \mathrm{Vid}$. ARANZADI. "La tutela judicial laboral...op. cit., pág. 24.

${ }^{89}$ Vid. SÁNCHEZ PÉREZ, J. (2019) "La reparación del daño en la jurisdicción laboral” en Revista Española de Derecho del Trabajo, Aranzadi, núm. 216/2019 Estudios, pág. 10.

${ }^{90}$ Así figura en el artículo 15 de la Directiva 2000/43/CE y en el artículo 18 de la Directiva 2000/78/CE.

${ }^{91} \mathrm{Vid}$. ARANZADI. "La tutela judicial laboral...op. cit., pág. 18.
} 
Superior de Justicia del País Vasco de 7 de julio de $2018^{92}$ recoge los criterios de la jurisprudencia en relación a los daños y perjuicios en el orden social. Se expone el criterio orientativo de fijar las indemnizaciones por daños morales en base a las cuantía fijadas en la LISOS $^{93}$. La STS del 8 de febrero de $2018^{94}$ resalta la necesidad de que en la demanda se fije la cuantía de la indemnización pretendida, desglosada en conceptos indemnizatorios, así como que en el caso en que el cálculo sea difícil se establecen de forma detallada las circunstancias que han de tenerse en cuenta para ponderar su cuantía; dicha sentencia también se pronuncia acerca de la importancia disuasoria de la indemnización.

El daño moral que se podría reclamar en los supuestos de discriminación múltiple sería difícil de cuantificar y por ello se entiende que al momento de interponer la demanda debe resaltarse esta cualidad de multiplicidad de la conducta discriminatoria para que esta sea tenida en cuenta por el juzgador a la hora de determinar la cuantía. En la Sentencia del Tribunal Superior de Justicia de las Islas Cataluña, de 2 de mayo de $2017^{95}$ se resuelve acerca de la pertinencia de una cuantía indemnizatoria, siendo el pronunciamiento a favor de dicha cuantía dada la mayor afectación a la trabajadora por concurrir una acumulación de circunstancia discriminatorias calificadas como discriminación múltiple.

Si bien con sus dificultades y limitaciones existe un procedimiento para recabar la tutela de los tribunales en los casos de discriminación en el acceso al empleo. Dado el escaso desarrollo sustantivo de la discriminación múltiple en el ordenamiento jurídico, la parte procesal no contempla estos supuestos. Sin embargo, si así se hiciera se incrementarían las garantías; como por ejemplo sucedería en el momento de fijar la cuantía indemnizatoria, atendiendo a una mayor apreciación de lo injusto.

\section{Los vacíos de justicia}

No tener en cuenta los supuestos de discriminación interseccional invisibiliza a los colectivos que se encuentran en dicha intersección. Esto sería un vacío de justicia en sí mismo y rige para todas las relaciones; sin embargo, este trabajo se centra en los vacíos de justicia que se originan en el acceso al empleo de la mujer en España. Se sigue la para la exposición de los mismos la exposición de los vacíos de justicia de Ruiz Santamaría que recoge los señalados por Márquez ${ }^{96}$.

El primer vacío que señala este autor es la ausencia de normas reguladoras ${ }^{97}$, en este caso se materializa en la falta de regulación de la discriminación múltiple, a lo que cabe sumar la dispersión de la regulación sobre discriminación. Esto puede traducirse en la invisibilización del problema de cara a implar medidas correctoras, así como en una tutela deficiente por parte de las administraciones y tribunales de la tutela de las personas más vulnerables. Para solventar esta falta de normativa debe tenerse en cuenta que la inclusión de la discriminación interseccional en los ordenamientos jurídicos debe hacerse de forma cautelosa, buscando integrar todas las causas de discriminación y todas las esferas, pues, tomando como ejemplo la próxima aprobación de la Directiva del Consejo por la que se aplica el principio de igualdad de trato entre las personas independientemente de su religión o convicciones, discapacidad, edad u orientación sexual, que recoge la discriminación múltiple, esta no recoge todas las características que pueden dar lugar a discriminación, por

\footnotetext{
${ }^{92} \mathrm{~N}^{\mathrm{o}}$ de Recurso: $1268 / 2018$.

${ }^{93}$ Vid. Sentencia del Tribunal Supremo, de 29 de noviembre de 2017, No . de Recurso: 7/2017.

${ }^{94}$ Vid. Sentencia del Tribunal Supremo, de 8 de febrero de 2018, No ${ }^{\circ}$ de Recurso.: 274/2016.

${ }^{95} \mathrm{~N}^{\circ}$ de Recurso: 818/2017.

${ }^{96}$ Vid. RUIZ SANTAMARÍA, José Luis. "El enfoque relacional como ... op. cit., págs. 65 y ss.

${ }^{97}$ Lo que A. Márquez señala como "ausencia de normas e instituciones indispensables para que las relaciones puedan funcionar según una estructura de red”. Ibídem., pág. 65.
} 
lo que aquellas que quedan fuera de dicha Directiva no podrían tenerse en cuenta, o tan solo cuando exista una intersección en los ámbitos estipulados por la Directiva ${ }^{98}$. Dejando un vacío en el resto de espacios e intersecciones.

Con respecto a la cobertura normativa otra de las posibles medidas para paliar este vacío es la ratificación por España del Convenio núm. 189 de la OIT ${ }^{99}$ que regula el empleo doméstico, un sector altamente feminizado, donde un gran porcentaje de las trabajadoras son migrantes y que además tiene unas altas tasas de irregularidad.

La falta de paridad y asimetría en la relación es otro de los vacíos de justicia, en este ámbito la condición de vulnerabilidad que se origina sitúa a las mujeres en una posición de inferioridad a la hora de negociar sus condiciones de incorporación al mercado de trabajo, llevándolas a aceptar condiciones peores que las que les corresponden por derecho e, incluso, abusivas. En relación con este aspecto cabe resaltar la nueva corriente de sindicalismo feminista que está tomando fuerza y que representa la lucha de las kelly's ${ }^{100}$ o la Asociación Jornaleras en lucha. Estos nuevos movimientos sitúan en la esfera pública los problemas asociados a estos sectores desde un enfoque feminista.

A partir del estudio realizado por Jiménez Rodrigo ${ }^{101}$ se pueden extraer vacíos de justicia ligados a las dimensiones de socialidad y reciprocidad. Esta investigadora señala barreras discriminatorias que impiden la incorporación al mercado de trabajo en condiciones de igualdad: el prejuicio de los agentes empleadores; las discriminaciones prelaborales, que son aquellas relacionadas con el nivel de formación demandado para accede a determinados empleos; o la segmentación del mercado de trabajo, que implica que determinados colectivos tengan mayor dificultada para acceder al mismo y se concentra en empleos de menor calidad. En conexión con esta última barrera nos encontramos los sectores altamente feminizados y con condiciones muy precarias, siendo el sector de los cuidados ejemplo de esto. Las cadenas de cuidados, anteriormente mencionadas, se constituyen como el ejemplo de la necesidad de que la justicia debe extenderse a todas las dimensiones, de modo contrario, esta no se realizará.

Cuando se produce la discriminación en el acceso al empleo, se puede dar un vació a la hora de reclamar los derechos vulnerados, cuyo origen es la desigual distribución de recursos ${ }^{102}$. No todas las mujeres tienen las mismas facilidades a la hora de acceder a la tutela judicial o incluso a denunciar ante la IT, en este sentido cabe resaltar la situación de las mujeres migrantes que trabajan en la agricultura y que se encuentran en situación irregular. El interponer una reclamación -en cualquiera de las vías- para estos colectivos de mujeres supone una dificultad añadida, en tanto que su situación irregular las paraliza a la hora de denunciar, por el miedo a ver afectada su permanencia en el país.

Estos son algunos de los vacíos de justicia que se desprenden de un primer análisis de

\footnotetext{
${ }^{98}$ Vid. CARRASQUEDO CEPEDA, M. (2017) "La mujer doblemente discriminada: una aproximación desde el Derecho Comunitario" en Revista Jurídica de Castilla y León, núm. 43, septiembre, 5-19, 2017, pág. 13. ${ }^{99}$ Vid. C189-Convenio sobre las trabajadoras y los trabajadores domésticos, 2011 (núm. 189) de la OIT. Este Convenio es destacable desde el punto de vista del presente trabajo, en tanto que además de la cuestión de género incorpora otros factores que pueden ser origen de vulnerabilidad, tales como la edad, y especialmente la condición de migrante de las personas que realizan este tipo de trabajo, así el artículo 8 de dicho Convenio persigue proteger la situación de las personas migrantes que realizan este trabajo -indistintamente de su sexo, si bien la alta representatividad de las mujeres en este sector permite referir la mayor protección que este instrumento internacional otorga a las mujeres migrantes que realizan trabajo doméstico-.

${ }^{100}$ Asociación de camareras de piso.

${ }^{101}$ Vid. JIMÉNEZ RODRIGO, M, (2018). “El abordaje...op. cit., págs. 206-207.

102 No solo de recursos materiales, sino también sociales -falta de apoyos-, o culturales -desconocimiento del idioma o de los mecanismos de denuncia disponibles-.
} 
la relación laboral, en particular del acceso al empleo de la mujer, teniendo en cuenta la discriminación interseccional.

\section{Conclusiones}

El análisis realizado evidencia como la interseccionalidad de factores discriminatorios ocasiona situaciones discriminatorias diferentes. Asimismo, el empleo del enfoque de género permite profundizar en el entendimiento de la situación de la mujer. El enfoque de la justicia relacional y su metodología asociada han permitido detectar aquellos vació de justicia que se dan en la relación laboral expuesta, el acceso al empleo. Esta combinación de enfoques y planteamientos aportan una perspectiva novedosa para la comprensión de realidades existentes.

El estudio legislativo, si bien muestra la implantación del principio de igualdad de trato a todos los niveles, no arroja mecanismos de protección en situaciones de discriminación múltiple. A la dispersión de la normativa antidiscriminación cabe sumarle la escasez de la misma. Esto se traduce en una falta de instrumentos específicos para que implementen los tribunales, debiendo ser estos los que introduzcan el concepto y establezcan mecanismos de compensación adecuados en tanto se desarrolla una normativa concreta.

El desarrollo legislativo en esta materia debería dirigirse a introducir de forma firme el concepto de discriminación múltiple en nuestro ordenamiento jurídico, para dar el amparo adecuado a estas situaciones, fijando unos criterios de aplicación para los Tribunales y la IT que reflejen un incremento de lo injusto cuando concurra más de una causa de discriminación. Una línea de investigación futura sería el estudio acerca de cómo introducir estos conceptos para que se introduzcan dentro de la normativa procesal.

En el ámbito institucional, la suscripción de aquellos acuerdos e instrumentos internacionales que trabajen en esta dirección es otro compromiso a adquirir, Como ya se ha señalado anteriormente, la ratificación por España del Convenio núm. 189 de la OIT favorecería la protección del trabajo doméstico, sector altamente feminizado, con una gran concentración de mujeres migrantes y con altas tasas de irregularidad.

Estos apuntes hechos sobre la dimensión de la institucionalidad, llevan intrínseco un pronunciamientos sobre la socialidad y reciprocidad que deberían articular las relaciones. Si se profundiza en la dimensión de la socialidad es necesario atender al cambio de valores imprescindible para que la justicia en los términos aquí expuestos pueda realizarse. Ejemplo de ello son las ya expuestas cadenas de cuidados, en las que un avance más lento en cuestión de asunción de estos valores de igualdad lleva a la externalización de la vulnerabilidad hacia otros grupos de mujeres. Por ello la importancia de atender a todos los grupos de mujeres en base a la intersección de sus condiciones, y de resultar ese cambio de valores que debe realizarse a nivel cultural.

En este sentido es destacable la existencia aún de ciertos prejuicios sobre el trabajo que pueden $-\mathrm{o}$ deben- realizar las mujeres, y que se ven agravados cuando concurren ciertas cualidades. Estos estereotipos que pueda tener el empleador a la hora de la contratación contaminan la relación laboral, dificultando el acceso al empleo en determinados sectores de ciertos grupos de mujeres o la pauperización de las condiciones laborales de los trabajos desempeñados por ellas.

La inclusión de estos planteamientos a la hora de diseñar, normas, planes de acción, medidas positivas, campañas de concienciación... Puede contribuir a mejorar la dimensión de la socialidad, dando visibilidad a ciertas situaciones y experiencias, lo que puede contribuir a una ampliación del concepto de justicia en términos de igualdad de género que 
incluya a un sujeto mujer más amplio, y esto repercutir en una mayor reciprocidad de las relaciones laborales. En este sentido se plantea como línea de investigación la profundización en el estudio de cómo se combinan las causas discriminatorias.

Los instrumentos teóricos aquí empleados buscaban resaltar la importancia de mejorar la integración de la mujer en el mercado de trabajo de forma cuantitativa, pero además revalorizando aquellos sectores más feminizados, ya que buscar un avance en términos de igualdad pero sin poner en valor los trabajos feminizados -tradicionalmente invisibilizados desde el punto de vista económico- origina estructuras jerárquicas dentro del grupo de mujeres, en relación a la distribución de recursos.

Este planteamiento implica una crítica intrínseca al mercado de trabajo, a las dinámicas de acceso al empleo y al sistema económico en el que se incardinan estas relaciones. La división entre trabajo productivo y reproductivo en la que se apoya el sistema capitalista y en su interacción con un sistema patriarcal, arroja como resultado la opresión de aquellas mujeres más vulnerables, situándolas en una situación de mayor riesgo de exclusión social y pobreza. El uso crítico de los conceptos aquí introducidos permite explorar otros marcos de relación que permitan una mayor justicia más allá de aquel impuesto por la lógica de la economía de mercado.

Las implicaciones de reconocer la existencia de discriminaciones múltiples e incluir mecanismos para erradicarlas en el ordenamiento jurídico son extrapolables a otras interseccionalidades, no solo a aquellas que incluyan el género entre las causas discriminatorias. Si bien, la reivindicación de este planteamiento desde el punto de vista del enfoque de género propuesto por el feminismo puede resultar interesante, en tanto que el principio de igualdad de trato entre mujeres y hombres goza de un buen sustento formal -si bien su realización material no avanza al mismo ritmo- y cierta trayectoria dentro de los ordenamientos jurídicos presentados. Ya que la idea implícita cuando se plantea la búsqueda de la justicia y de la igualdad real en términos redistributivos, representativos y de participación desde el feminismo no es dotar de esta igualdad a determinados grupos de población diferenciados de otros, sino que esta se extienda a todas las personas. 


\section{Bibliografía}

- AGENCIA DE LOS DERECHOS FUNDAMENTALES DE LA UNIÓN EUROPEA (2011), "Manual de legislación europea contra la discriminación”, Luxemburgo.

- ALEMANY ZARAGOZA, E. (2005) "Evolución histórica del trabajo de la mujer hasta nuestros días", en Revista Doctrinal Aranzadi Social, núm. 22/2004 parte Estudio .

- AMORÓS, C. y DE MIGUEL, A. (2014), Teoría feminista: de la ilustración al segundo sexo, vol. 1.

- APECECHEA CELAYA, C. (2016), “Actuaciones de la Inspección de trabajo y Seguridad Social para la vigilancia en las empresas de la igualdad entre mujeres y hombres" en Estudios sobre los diversos aspectos jurídicos del trabajo de la mujer, Aranzadi, Enero.

- ARANZADI. "La tutela judicial laboral antidiscriminación en el acceso a un puesto de trabajo a través del proceso de tutela de derechos fundamentales y libertados públicas". En Cuadernos de Aranzadi Social. Estadios previos al contrato de trabajo y discriminación, enero de 2013.

- ARRUZZA, C., BHATTACHARYA, T. y FRASER, N., (2019), Manifiesto de un feminismo para el 99\%. Herder Editorial.

- CARRASQUEDO CEPEDA, M. (2017) "La mujer doblemente discriminada: una aproximación desde el Derecho Comunitario" en Revista Jurídica de Castilla y León, núm. 43, septiembre, 5-19, 2017.

- CRENSHAW, K., (1989), "Demarginalizing the Intersection of Race and Sex: A Black Feminist Critique of Antidiscrimination Doctrine, Feminist Theory and Antiracist Politics" en University of Chicago Legal Forum, vol. 1989, art. 8.

- DONATI, P. (2006), Repensar la sociedad: el enfoque relacional. Madrid: Ediciones Internacionales Universitarias.

- FRASER, N. (2012), "La política feminista en la era del reconocimiento: un enfoque bidimensional de la justicia de género" en Arenal. Revista de Historia de las Mujeres, núm. 19, vol. 2 julio-diciembre.

- FRASER, N. (2020), "Las contradicciones del capital y de los cuidados" en FRASER N. Los talleres ocultos del capital. Un mapa para la izquierda. Traficantes de Sueños.

- FREDMAN, S. (2016), "Intersectional discrimination in EU gender equality and nondiscrimination law", en Directorate-General for Justice and Consumers.

- IGLESIAS, C. (2012), "Justicia como redistribución, reconocimiento y representación: las reconciliaciones de Nancy Fraser" en Investigaciones Feministas, vol. 3.

- JIMÉNEZ RODRIGO, M. (2018) "El abordaje de la discriminación múltiple en el empleo: Revisión de políticas y buenas prácticas en la Unión Europea” en Revista Internacional y Comparada de Relaciones Laborales y Derecho del Empleo, vol. 6, núm. 3, julio-septiembre.

- MÁRQUEZ PRIETO, A. (2017), “Justicia relacional: enfoque, línea y método”, en MÁRQUEZ PRIETO, A.: Justicia relacional y principio de fraternidad. Navarra: Aranzadi. 
- MORÁN BLANCO, S. (2018), "El <<trabajo decente〉> en la UE: políticas y normas" en Revista Española de Derecho del Trabajo, núm. 206/2018 parte Estudios.

- NOGUEIRA DOMÍNGUEZ, J. y ZALAKAIN HERNÁNDEZ, J. (2015) "La discriminación múltiple de las mujeres extranjeras que trabajan en servicios domésticos y de cuidados a dependientes en Euskadi” en Zerbitzuan: Gizarte zerbitzuetarako aldizkaria, núm. 60.

- ORGANIZACIÓN INTERNACIONAL PARA LAS MIGRACIONES (2016), Estudio sobre la situación laboral de la mujer en España, Ministerio de Empleo y Seguridad Social.

- RIVAS VALlEJO, P. (2020), "Perspectiva de género en el tratamiento de la discapacidad: incidencia laboral y de seguridad social" en La discapacidad en el marco de las relaciones laborales, octubre-noviembre.

- RODRÍGUEZ CRESPO, María José. "Límites a la libertad contractual: igualdad y no discriminación en materia de intermediación, selección y contratación" en Revista Doctrinal Aranzadi Social núm. 2/2013 Informes, 2013.

- RUIZ SANTAMARÍA, J. (2020), "El enfoque relacional como metodología de análisis en el Derecho del trabajo: el expediente de inclusión frente a la discriminación laboral" en Revista Jurídica de Investigación e Innovación Educativa (REJIE Nueva Época), núm. 21.

- SALAS PORRAS, M. (2017), "Replanteamiento jurídico de los fundamentos y finalidades de la política activa de empleo desde el enfoque de justicia relacional", en MÁRQUEZ PRIETO, A.: Justicia relacional y principio de fraternidad. Navarra: Aranzadi.

- SÁNCHEZ PÉREZ, J. (2019) “La reparación del daño en la jurisdicción laboral” en Revista Española de Derecho del Trabajo, Aranzadi, núm. 216/2019 Estudios.

- SMART, C. (2017), "La búsqueda de una teoría feminista del derecho" en Delito y Sociedad, 1 (11/12).

- UGT, Área Confederal LGTBI [En línea $]$ http://www.ugt.es/sites/default/files/resumen-ejecutivo1.pdf. 